\title{
Passivation of surface and bulk defects in $p$-GaSb by hydrogenated amorphous silicon treatment
}

\author{
P. S. Dutta, A. K. Sreedhar, and H. L. Bhat ${ }^{a)}$ \\ Department of Physics, Indian Institute of Science, Bangalore - 560 012, India
}

G. C. Dubey and Vikram Kumar

Solid State Physics Laboratory, Lucknow Road, Delhi - 110 054, India

E. Dieguez

Departamento de Fisica de Materiales, Universidad Autonoma, C-IV, 28049 Cantoblanco-Madrid, Spain

U. Pal and J. Piqueras

Departamento de Fisica de Materiales, Facultad de Fisica, Universidad Complutense, 28040 Madrid, Spain

(Received 10 October 1995; accepted for publication 27 November 1995)

\begin{abstract}
Passivation of point and extended defects in GaSb has been observed as a result of hydrogenated amorphous silicon $(a-\mathrm{Si}: \mathrm{H})$ treatment by the glow discharge technique. Cathodoluminescence (CL) images recorded at various depths in the samples clearly show passivation of defects on the surface as well as in the bulk region. The passivation of various recombination centers in the bulk is attributed to the formation of hydrogen-impurity complexes by diffusion of hydrogen ions from the plasma. $a-\mathrm{Si}: \mathrm{H}$ acts as a protective cap layer and prevents surface degradation which is usually encountered by bare exposure to hydrogen plasma. An enhancement in luminescence intensity up to 20 times is seen due to the passivation of nonradiative recombination centers. The passivation efficiency is found to improve with an increase in $a$-Si:H deposition temperature. The relative passivation efficiency of donors and acceptors by hydrogen in undoped and Te-compensated $p$-GaSb has been evaluated by $\mathrm{CL}$ and by the temperature dependence of photoluminescence intensities. Most notably, effective passivation of minority dopants in tellurium compensated $p$-GaSb is evidenced for the first time. (c) 1996 American Institute of Physics. [S0021-8979(96)03105-4]
\end{abstract}

\section{INTRODUCTION}

In recent times, extensive research has been carried out on defect passivation in various elemental and compound semiconductors. This is interesting both for understanding the physics of the material as well as from the point of view of technological applications. Several techniques have been used for passivating the bulk as well as surface defects. Usually, chemical treatment with sulfur-containing compounds like $\left(\mathrm{NH}_{4}\right)_{2} \mathrm{~S}_{x}, \mathrm{Na}_{2} \mathrm{~S}, \mathrm{H}_{2} \mathrm{~S}$ results in surface reconstruction due to which the surface recombination rate decreases. ${ }^{1-3} \mathrm{On}$ the other hand, defects in the bulk are passivated by indiffusion of light elements like lithium, hydrogen, etc. ${ }^{4}$ These elements reduce the concentration of various defect centers by forming complexes with them. Passivation by hydrogen plasma has been widely used in the recent past. ${ }^{4}$ Even though passivation of bulk defects by hydrogen is now well established, avoiding surface degradation during plasma exposure is not trivial. ${ }^{4}$ The surface defect layer thus created adversely affects the electrical and optical properties of the material. A lot of effort has been made to avoid the formation of the defect layer in various materials (see Ref. 4 and references therein). Recently, we have been investigating the applicability of various surface passivation methods to $\mathrm{GaSb},{ }^{5,6}$ a III-V compound semiconductor that is gaining importance. ${ }^{7}$ A previous investigation on hydrogenation of $\mathrm{GaSb}$ by a $\mathrm{rf}$

\footnotetext{
a) Author to whom all correspondence should be addressed; Electronic mail: hlbhat@physics.iisc.ernet.in
}

plasma technique has already demonstrated the existence of a surface defect layer. ${ }^{8}$ By slow chemical etching, it has been found possible to remove this defect layer. ${ }^{9}$ But this approach is limited only to basic research and is impractical in device fabrication processes. Hence, it would be highly desirable to develop some dry processing techniques for either removing or passivating the surface defects. Deposition of the surface layer of a different material can be beneficial in this respect, which along with its passivating effect can also act as a stable, protective layer. One such candidate can be $a-\mathrm{Si}: \mathrm{H}$, which has been extensively used for thin film transistors and high efficiency solar cell applications. ${ }^{10}$ To the best of our knowledge, such a study has not been attempted until now on GaSb. This article discusses the photoluminescence (PL) and cathodoluminescence (CL) properties of $a$-Si:H treated undoped and tellurium-compensated $p$-GaSb. The results obtained herein clearly demonstrate the effectiveness of this treatment in achieving bulk passivation due to the plasma hydrogen in addition to a defect-free surface terminated by $a-\mathrm{Si}: \mathrm{H}$.

\section{EXPERIMENTAL DETAILS}

The single-crystal substrates of undoped and Tecompensated $p$-GaSb used for our studies were grown by the vertical Bridgman technique. ${ }^{11}$ Various degrees of Te compensation were obtained by a repeated dilution process. Initially, Te-doped $n$-GaSb crystals were grown with the carrier 
concentration $\sim 10^{17} \mathrm{~cm}^{-3}$. Then, a small weighed quantity of a Te-doped $n$-GaSb ingot was added to a fresh charge of undoped $\mathrm{GaSb}$ for the next growth run. This dilution procedure was repeated for successive growth experiments until the required level of net acceptor concentration was obtained. Layers of $a-\mathrm{Si}: \mathrm{H}$ with thicknesses in the range of 100-200 $\AA$ were deposited on the substrates using a radio frequency plasma glow discharge system ${ }^{12}$ with a rf power of $6 \mathrm{~W} / \mathrm{cm}^{2}$. Substrate temperatures in the range of $150-300{ }^{\circ} \mathrm{C}$ were employed. A mixture of $1 \% \mathrm{SiH}_{4}$ in $99 \% \mathrm{H}_{2}$ with a flow rate of $1 \mathrm{cc} / \mathrm{min}$ was found to be optimal for obtaining high quality amorphous films.

The CL measurements were carried out using a Hitachi S-2500 scanning electron microscope in the emissive and CL modes at $80 \mathrm{~K} .{ }^{13}$ The advantage of $\mathrm{CL}$, in addition to the high spatial resolution, is its ability to obtain more detailed depth-resolved information by varying the electron beam energy. ${ }^{14}$ The accelerating voltage was in the range of $10-20$ $\mathrm{keV}$. The beam current was kept constant at $100 \mathrm{nA}$. These beam parameters were found sufficient to give enough luminescence intensity to carry out the measurements without causing excessive heating and self-absorption. ${ }^{15}$ The panchromatic CL images were recorded using a system consisting of an optical focusing lens and a liquid-nitrogen-cooled North Coast EO-817 germanium detector attached to the microscope. To record the CL spectra, an optical fiber guide feeding the light to an Oriel 78215 computer-controlled monochromator was used. From previous studies, it has been found that by defocusing the electron beam, it is possible to observe centers with low concentrations. ${ }^{16}$ For this reason, CL spectra were recorded both under focusing and defocusing conditions of the electron beam.

The PL measurements were carried out using MIDAC Fourier transform photoluminescence spectrometer. An argon ion laser operating at $5145 \AA$ was used as the excitation source with excitation levels in the range of $0.166-3.5$ $\mathrm{W} / \mathrm{cm}^{2}$. A liquid-nitrogen-cooled germanium photodetector was employed for signal detection. A resolution of $0.5 \mathrm{meV}$ was used in our measurements. For low temperature measurements, the samples were freely suspended in liquid $\mathrm{He}$ at $4.2 \mathrm{~K}$. To study the temperature dependence of PL, the spectra were recorded during the natural heating cycle after the evaporation of liquid He. The temperature variation during the data acquisition for any spectrum was less than $0.5^{\circ} \mathrm{C}$. The carrier concentrations of various samples used in our studies were evaluated by the room temperature Hall measurements.

\section{RESULTS AND DISCUSSION}

\section{A. Panchromatic cathodoluminescence images}

Figure 1 shows a typical CL image recorded on a polished GaSb wafer prepared from the as-grown sample. Defects typical of melt grown crystals have been identified and marked. These include cellular dislocation network (D), precipitates or impurity clusters $(\mathrm{P})$, and twin boundaries (parallel lines marked T). The distribution of defects in the samples remains the same irrespective of the depth. After $a$-Si:H treatment, there was a complete disappearance of the

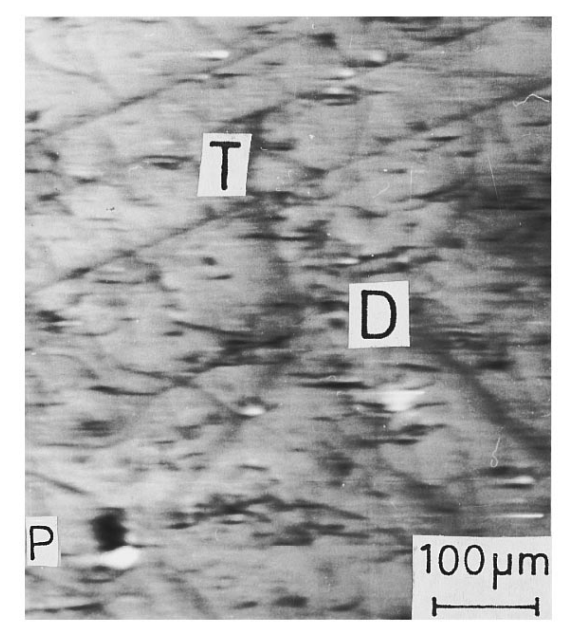

FIG. 1. Typical CL image of a polished GaSb wafer from an as-grown crystal recorded with $E_{b}=10 \mathrm{keV}$. The labels marked as T, D, and P represent twins, dislocation networks, and precipitates, respectively.

dislocation network. Here, it is worth mentioning that the disappearance of these nonradiative centers is a result of passivation by hydrogen rather than their elimination. To rule out the possibility of reduction in dislocation due to thermal effects during the glow discharge treatment, some of the untreated samples (as grown) were annealed at $300{ }^{\circ} \mathrm{C}$ for $1 \mathrm{~h}$. The CL images recorded before and after the treatment were exactly identical, verifying that the passivation of dislocations in the treated samples is caused by hydrogen and not due to mere thermal annealing. Passivation of extended defects like grain boundaries and dislocations in GaSb by hydrogen has been observed in our previous electrical studies also. ${ }^{9}$ From the contrast of the CL images it was inferred that the samples are better passivated at higher temperatures. Furthermore, some of the samples passivated at $300{ }^{\circ} \mathrm{C}$ were annealed in $\mathrm{N}_{2}$ atmosphere at the same temperature for $1 \mathrm{~h}$. No changes were observed in the images recorded after thermal treatment. This shows high thermal stability of the passivated extended defects. This is in agreement with earlier measurements carried out on hydrogenated polycrystalline $\mathrm{GaSb}^{9}$

To evaluate the depth of which hydrogen passivation has occurred, CL images were recorded with increasing accelerating voltages up to $20 \mathrm{keV}$. The general expression derived by Kanaya and Okayama ${ }^{17}$ for the range of electron penetration $R_{e}$ as a function of electron beam energy $E_{b}$ is

$$
R_{e}=\left(0.0276 \mathrm{~A} / \rho Z^{0.889}\right) E_{b}^{1.67}(\mu \mathrm{m}),
$$

where $E_{b}$ is in $\mathrm{keV}, A$ is the atomic weight in $\mathrm{g} / \mathrm{mol}, \rho$ is in $\mathrm{g} / \mathrm{cm}^{3}$, and $Z$ is the atomic number. The $R_{e}$ in our case with $E_{b}$ varying from 10 to $20 \mathrm{keV}$ lies in the range of $0.87-2.78$ $\mu \mathrm{m}$. Typical CL images recorded with accelerating voltages of 10 and $20 \mathrm{keV}$ for the Te-compensated GaSb with $a$-Si:H deposited at $150{ }^{\circ} \mathrm{C}$ are shown in Figs. 2(a) and 2(b), respectively. Complete passivation of the dislocations and twin boundaries can be seen in Fig. 2(a) even at higher magnification. At low $E_{b}$, the penetration depth of the electrons is less and hence the surface-related recombination can be visualized better. With an increase in $E_{b}$ to $20 \mathrm{keV}$ (corre- 


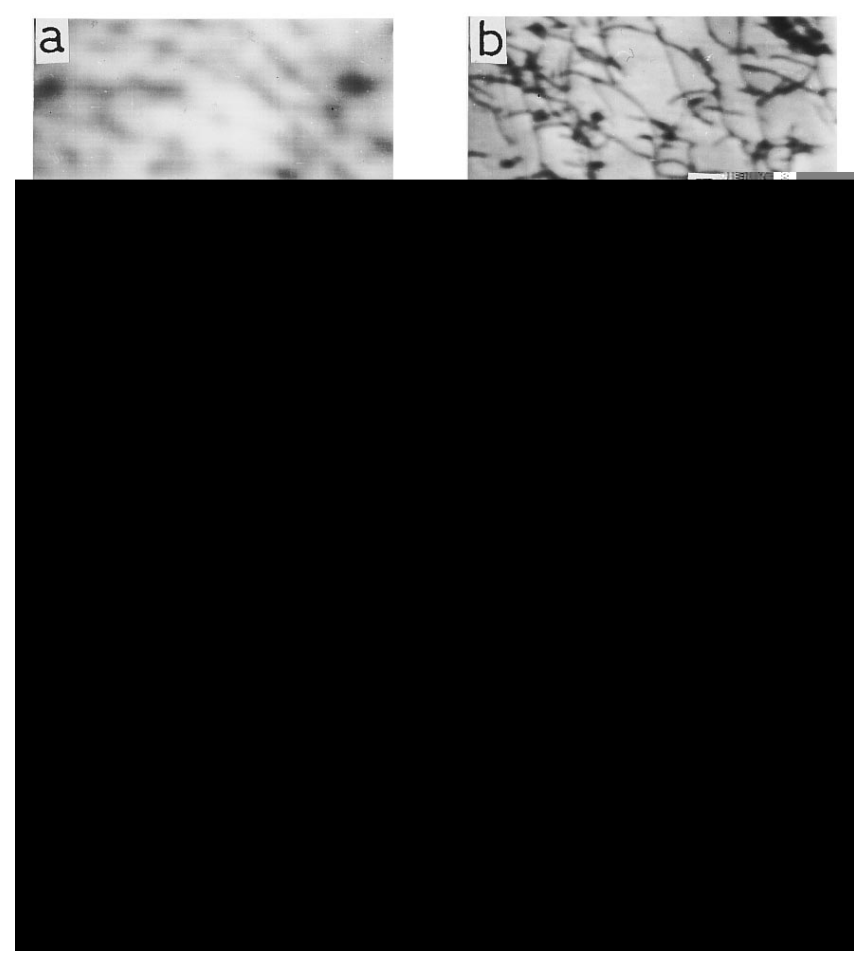

FIG. 2. Panchromatic CL images of Te-compensated $p$-GaSb with (a) $a$-Si:H deposited at $150{ }^{\circ} \mathrm{C}\left(E_{b}: 10 \mathrm{keV}\right)$; (b) $a$-Si:H deposited at $150{ }^{\circ} \mathrm{C}$ $\left(E_{b}: 20 \mathrm{keV}\right)$; (c) $a$-Si:H deposited at $300{ }^{\circ} \mathrm{C}\left(E_{b}: 10 \mathrm{keV}\right)$; (d) $a-\mathrm{Si}: \mathrm{H}$ deposited at $300{ }^{\circ} \mathrm{C}\left(E_{b}: 20 \mathrm{keV}\right)$.

sponding to a depth of $2.8 \mu \mathrm{m}$ ), defects in the bulk are revealed [image 2(b)]. The dislocation network as observed in the CL image of the passivated sample at higher accelerating voltage [image 2(b)] is similar to that observed in an unpassivated sample (Fig. 1). The depth to which passivation occurs has been found to depend on the $a-\mathrm{Si}: \mathrm{H}$ deposition temperature. The CL images of the sample passivated at $300{ }^{\circ} \mathrm{C}$ are shown in Figs. 2(c) and 2(d) for the same region with an $E_{b}$ of 10 and $20 \mathrm{keV}$, respectively. A comparison of the CL images recorded at the same depth [Figs. 2(b) and 2(d)] for the samples passivated at 150 and $300{ }^{\circ} \mathrm{C}$ show that the depth of passivation increases with increase in deposition temperature. Even at $2.8 \mu \mathrm{m}$, the effect of passivation can be seen in the sample treated at $300{ }^{\circ} \mathrm{C}$.

\section{B. Cathodoluminescence spectra}

The CL spectra recorded at $10 \mathrm{keV}$ for the undoped samples before and after $a-\mathrm{Si}: \mathrm{H}$ treatment at $150{ }^{\circ} \mathrm{C}$ are shown in Fig. 3. The broad spectrum for the unpassivated sample [spectrum (i)] has been deconvoluted into four main peaks at 704, 775, 805, and $830 \mathrm{meV}$. The above-band-gap peak at $830 \mathrm{meV}$ is an $(e, h)$ transition including tail states and shallow acceptors ${ }^{18}$ arising due to high excitation intensities in CL. The $805 \mathrm{meV}$ is the band-gap-related peak. The 775 and $704 \mathrm{meV}$ peaks are due to the transitions from the conduction band to neutral state and singly ionized state of the native acceptor level, respectively. The passivated sample [spectrum (ii)] shows an overall enhancement in the CL intensity along with an increase in the relative intensity of the $704 \mathrm{meV}$ peak compared to the $775 \mathrm{meV}$ transition. The

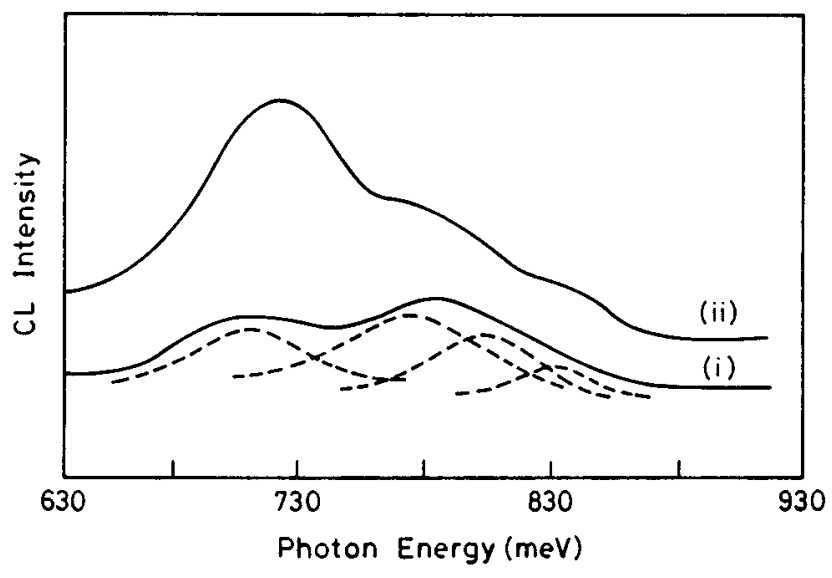

FIG. 3. CL spectra of undoped $p$-GaSb: (i) without an $a-\mathrm{Si}: \mathrm{H}$ layer; (ii) with an $a$-Si:H layer deposited at $150{ }^{\circ} \mathrm{C}\left(E_{b}=10 \mathrm{keV}\right)$. The dashed curves are the deconvoluted peaks of spectrum (i).

higher CL intensity of the passivated sample is attributed to the reduction in nonradiative recombination channels. The reason for the relative increase in the $704 \mathrm{meV}$ transition will be discussed later.

The CL spectra of the Te-compensated samples before and after $a$-Si:H treatment at $150{ }^{\circ} \mathrm{C}$ are shown in Fig. 4 . Apart from the four peaks seen in the undoped samples, a new peak at $730 \mathrm{meV}$ appears [spectrum (i)]. The $730 \mathrm{meV}$ transition is intrinsic to tellurium and is attributed to a transition from the conduction band to the deep $\mathrm{V}_{\mathrm{Ga}} \mathrm{Ga}_{\mathrm{Sb}} \mathrm{Te}_{\mathrm{Sb}}$ center. ${ }^{19}$ After $a$-Si:H treatment, the CL intensity increases by at least five times due to passivation of the nonradiative recombination centers. Apart from the increase in the luminescence efficiency, the peaks at 704 and $730 \mathrm{meV}$ are absent in the passivated sample in the near-surface region [spectrum (ii)]. Also, the broad peak encompassing the 775,805 , and $830 \mathrm{meV}$ transitions is better resolved. With an increase in $E_{b}$ to $20 \mathrm{keV}$, luminescence from the bulk region is observed and the CL spectrum show a reappearance of the 704 and $730 \mathrm{meV}$ peaks [spectrum (iii)]. Also a slight decrease in the

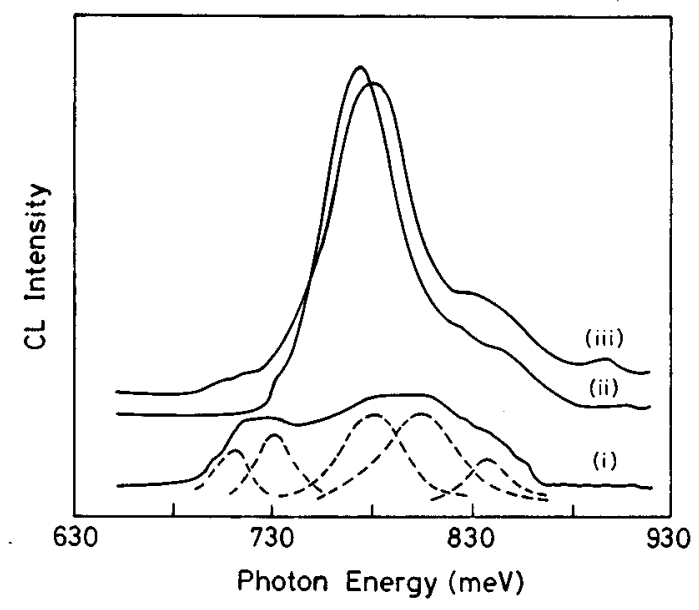

FIG. 4. CL spectra of Te-compensated $p$-GaSb: (i) before $a$-Si:H deposition; (ii) after $a$-Si:H deposited at $150{ }^{\circ} \mathrm{C}$ and $E_{b}=10 \mathrm{keV}$ ); (iii) after $a-\mathrm{Si}: \mathrm{H}$ deposited at $150{ }^{\circ} \mathrm{C}$ and $E_{b}=20 \mathrm{keV}$ ). The dashed curves are the deconvoluted peaks of spectrum (i). 


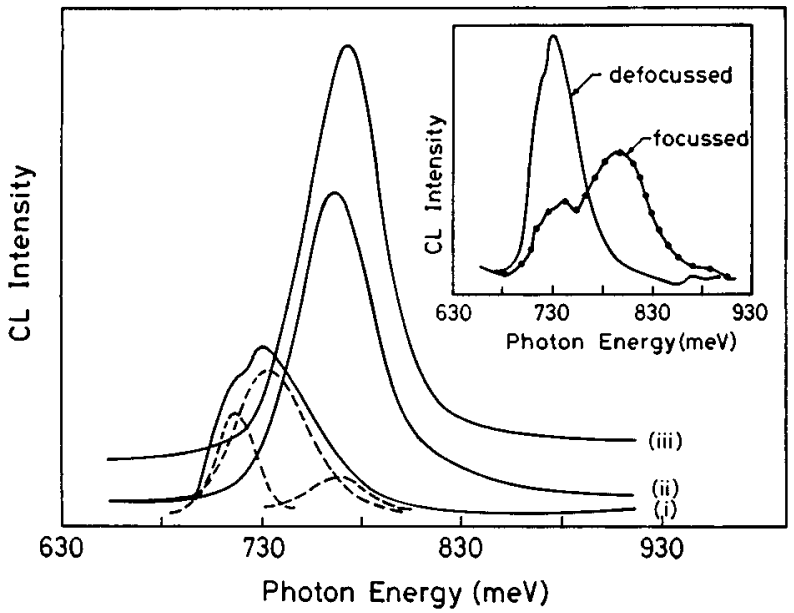

FIG. 5. CL spectra of Te-compensated $p$-GaSb recorded with a defocused electron beam: (i) without an $a$-Si:H layer, (ii) with an $a$-Si:H layer deposited at $250{ }^{\circ} \mathrm{C}$; (iii) with an $a$-Si:H layer deposited at $300{ }^{\circ} \mathrm{C}$. The dashed curves are the deconvoluted peaks of spectrum (i). The insert in this figure shows the CL spectra of the unpassivated sample with focused and defocused electron beams.

dominant peak intensity is observed. This is expected as the corresponding CL image [Fig. 2(b)] shows unpassivated defects in the bulk. However, the intensities of the 704 and 730 meV peaks do not attain their original level, indicating that these centers are only partially passivated. For the samples passivated at higher temperatures, say $200-300{ }^{\circ} \mathrm{C}$, even with an $E_{b}$ of $20 \mathrm{keV}$, the peaks at 704 and $730 \mathrm{meV}$ do not appear indicating effective passivation to greater depths.

The CL spectra recorded for the unpassivated Tecompensated $\mathrm{GaSb}$ (i) and the corresponding samples passivated at $250{ }^{\circ} \mathrm{C}$ (ii) and $300{ }^{\circ} \mathrm{C}$ (iii) employing a defocused electron beam are shown in Fig. 5. For the sake of comparison, the CL spectra for the unpassivated sample recorded with focused as well as defocused beams are shown in the insert of Fig. 5. As can be seen from the insert, the unpassivated sample shows an increase in the intensities of the deep levels at 704 and $730 \mathrm{meV}$ on defocusing. Referring to spectra (i), (ii), and (iii) of Fig. 5, the $a$-Si:H treated samples show complete passivation of the deep centers. It should be noted that the defocused spectra for the passivated samples shown here are essentially similar to those observed under focused conditions. A focused electron beam results in saturation of the emission. At high levels of excitation, the luminescent centers become filled by capturing minority carriers. As the centers are filled, the excess minority carriers in the conduction band recombine through nonradiative centers in the bulk. In the absence of the bulk nonradiative recombination centers, the diffusion length increases and carriers diffuse to the surface and recombine. However, by defocusing the electron beam, the saturation of the recombination centers can be avoided and thus recombination centers with low concentrations in the material can be seen. ${ }^{16}$ The very fact that there are no observable centers with low concentration in the $a$-Si:H treated samples confirms the passivation of bulk defects by hydrogen.

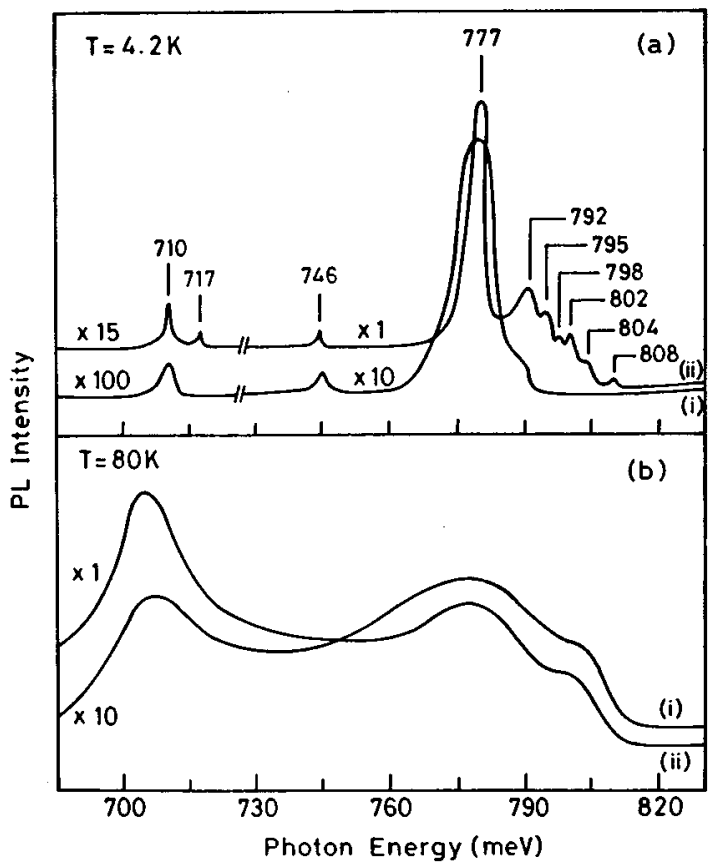

FIG. 6. PL spectra of undoped $p$-GaSb recorded at (a) $4.2 \mathrm{~K}$ and (b) $80 \mathrm{~K}$ : (i) without an $a-\mathrm{Si}: \mathrm{H}$ layer; (ii) with an $a-\mathrm{Si}: \mathrm{H}$ layer.

\section{Photoluminescence spectra}

The PL spectra recorded at $4.2 \mathrm{~K}$ for the undoped samples before and after $a$-Si:H deposition at $200^{\circ} \mathrm{C}$ are shown in Fig. 6(a). An increase in PL intensity of the dominant transition by $\sim 12$ times is seen after passivation. Moreover, several near-band-edge excitonic peaks in the range of 792-808 $\mathrm{meV}$ and a peak at $717 \mathrm{meV}$ corresponding to an exciton bound to the ionized native acceptor appear. Various peaks appearing in the PL spectrum of bulk GaSb have been assigned earlier ${ }^{18,20}$ and are given in Table I. For the sake of completeness, the peaks observed in CL spectra discussed in the previous section are also listed. The enhancement in PL intensity and the appearance of additional peaks is a cumulative effect of defect passivation in the bulk as well as on the surface as discussed below. It is known from earlier studies that plasma hydrogen passivates shallow and deep centers in the bulk. ${ }^{9}$ However, at the same time, the sample surface degrades. ${ }^{8}$ The defective surface layer had to be removed by chemical etching before carrying out any optical and electrical characterization. Thus, even though an overall improvement in the luminescence intensity as a result of bulk defect passivation was seen, the well-resolved excitonic features were absent. ${ }^{9}$ This simply reflects the presence of surface recombination centers in these samples left behind after etching. On the other hand, passivation of the surface dangling bonds by either $\left(\mathrm{NH}_{4}\right)_{2} \mathrm{~S}_{x}$ (Ref. 5) or $\mathrm{RuCl}_{3}$ (Ref. 6) results in well-resolved near-band-edge excitonic peaks. This is due to the reduction in the recombination centers of the excitons at the surface. The improvement in overall PL intensity and the presence of well-resolved excitonic peaks in $a-\mathrm{Si}: \mathrm{H}$ treated samples [Fig. 6(a)] clearly demonstrates the efficient passivation of both surface and bulk defects. 
TABLE I. PL and CL transitions observed in bulk GaSb.

\begin{tabular}{|c|c|c|}
\hline \multicolumn{2}{|c|}{ Energy (meV) } & \multirow[b]{2}{*}{ Transition } \\
\hline $\begin{array}{l}\text { PL data } \\
(4.2 \mathrm{~K})\end{array}$ & $\begin{array}{c}\text { CL data } \\
(80 \mathrm{~K})\end{array}$ & \\
\hline $\begin{array}{l}830^{\mathrm{a}} \\
(77 \mathrm{~K})\end{array}$ & $830^{\mathrm{b}}$ & $(e, h)$ recombination \\
\hline $812^{\mathrm{a}}$ & $805^{\mathrm{b}}$ & Band gap \\
\hline $810^{\mathrm{a}, \mathrm{c}}$ & & Free exciton \\
\hline $808^{\mathrm{b}}$ & & Excitonic transition \\
\hline $807^{\mathrm{b}}$ & & Excitonic transition \\
\hline $805^{\mathrm{b}}$ & & $\begin{array}{l}\text { Exciton bound to } \\
\qquad\left(\mathrm{V}_{\mathrm{Ga}} \mathrm{Ga}_{\mathrm{Sb}}\right)^{0}\end{array}$ \\
\hline $803^{\mathrm{b}}$ & & $\begin{array}{l}\text { Exciton bound to } \\
\qquad\left(\mathrm{V}_{\mathrm{Ga}} \mathrm{Ga}_{\mathrm{Sb}}\right)^{0}\end{array}$ \\
\hline $801^{\mathrm{d}}$ & & $\mathrm{D}^{+}-\mathrm{Si}$ acceptor \\
\hline $800^{\mathrm{b}}$ & & $\begin{array}{l}\text { Exciton bound to } \\
\qquad\left(\mathrm{V}_{\mathrm{Ga}} \mathrm{Ga}_{\mathrm{Sb}}\right)^{0}\end{array}$ \\
\hline $797^{\mathrm{c}, \mathrm{e}}$ & & Excitonic transition \\
\hline $796^{\mathrm{b}}$ & & $\begin{array}{l}\text { Exciton bound to } \\
\qquad\left(\mathrm{V}_{\mathrm{Ga}} \mathrm{Ga}_{\mathrm{Sb}}\right)^{0}\end{array}$ \\
\hline $795^{\mathrm{b}}$ & & Excitonic transition \\
\hline $792^{\mathrm{b}, \mathrm{d}}$ & & $\begin{array}{l}\text { Exciton bound to } \\
\qquad\left(\mathrm{V}_{\mathrm{Ga}} \mathrm{Ga}_{\mathrm{Sb}}\right)^{0}\end{array}$ \\
\hline $781^{\mathrm{b}, \mathrm{d}}$ & $775^{\mathrm{b}}$ & $\mathrm{C}-\left(\mathrm{V}_{\mathrm{Ga}} \mathrm{Ga}_{\mathrm{Sb}}\right)^{0}$ \\
\hline $777^{\mathrm{d}}$ & & $\mathrm{D}^{+}-\left(\mathrm{V}_{\mathrm{Ga}} \mathrm{Ga}_{\mathrm{Sb}}\right)^{0}$ \\
\hline $775^{\mathrm{d}}$ & & $\mathrm{C}-\mathrm{Zn}$ acceptor \\
\hline $746^{\mathrm{d}}$ & & $\begin{array}{l}\text { LO phonon replica } \\
\text { of } 777 \mathrm{meV}\end{array}$ \\
\hline $740^{\mathrm{d}}$ & $730^{\mathrm{b}}$ & $\mathrm{C}-\left(\mathrm{V}_{\mathrm{Ga}} \mathrm{Ga}_{\mathrm{Sb}} \mathrm{Te}_{\mathrm{Sb}}\right)^{0}$ \\
\hline $717^{\mathrm{d}}$ & & $\begin{array}{l}\text { Exciton bound to } \\
\qquad\left(\mathrm{V}_{\mathrm{Ga}} \mathrm{Ga}_{\mathrm{Sb}}\right)^{-}\end{array}$ \\
\hline $710^{\mathrm{d}}$ & $704^{b}$ & $\mathrm{C}-\left(\mathrm{V}_{\mathrm{Ga}} \mathrm{Ga}_{\mathrm{Sb}}\right)^{-}$ \\
\hline
\end{tabular}

${ }^{\mathrm{a}}$ Reference 18 .

${ }^{\mathrm{b}}$ This work.

${ }^{\mathrm{c}}$ Reference 5 .

${ }^{\mathrm{d}}$ Reference 20.

${ }^{\mathrm{e}}$ Reference 6.

In Fig. 6(a), the dominant peak is the donor-acceptor (D-A) pair transition at $777 \mathrm{meV}$ (see Table I). In the unpassivated sample, this peak was found to shift toward higher energy by 2-3 meV per decade increase in laser power density. However in the passivated sample, the observed peak shift is around 8-9 meV per decade increase in excitation intensity. This large D-A pair peak shift is due to an increase in compensation ${ }^{21}$ resulting from more efficient passivation of acceptors compared to donors. At $80 \mathrm{~K}$, for the unpassivated sample, the intensity of $704 \mathrm{meV}(710 \mathrm{meV}$ at $4.2 \mathrm{~K})$ peak is slightly lower than that of $775 \mathrm{meV}(777$ $\mathrm{meV}$ at $4.2 \mathrm{~K}$ ). However, in passivated samples, the intensity of the $704 \mathrm{meV}$ peak is higher than that of $775 \mathrm{meV}$. Also note that there is an overall increase in the intensity by $\sim 10$ times as a result of passivation. The relative increase of the $704 \mathrm{meV}$ peak after passivation was also seen in CL measurements (Fig. 3).

Figures 7(a) and 7(b) show the PL spectra recorded at 4.2 and $80 \mathrm{~K}$, respectively, for the Te-compensated samples before and after passivation at $200{ }^{\circ} \mathrm{C}$. At $4.2 \mathrm{~K}$, the passivated sample shows at least a 10 times improvement in luminescence intensity of the $781 \mathrm{meV}$ dominant transition with better resolution than the unpassivated ones. The 781 $\mathrm{meV}$ peak corresponds to the transition from the conduction

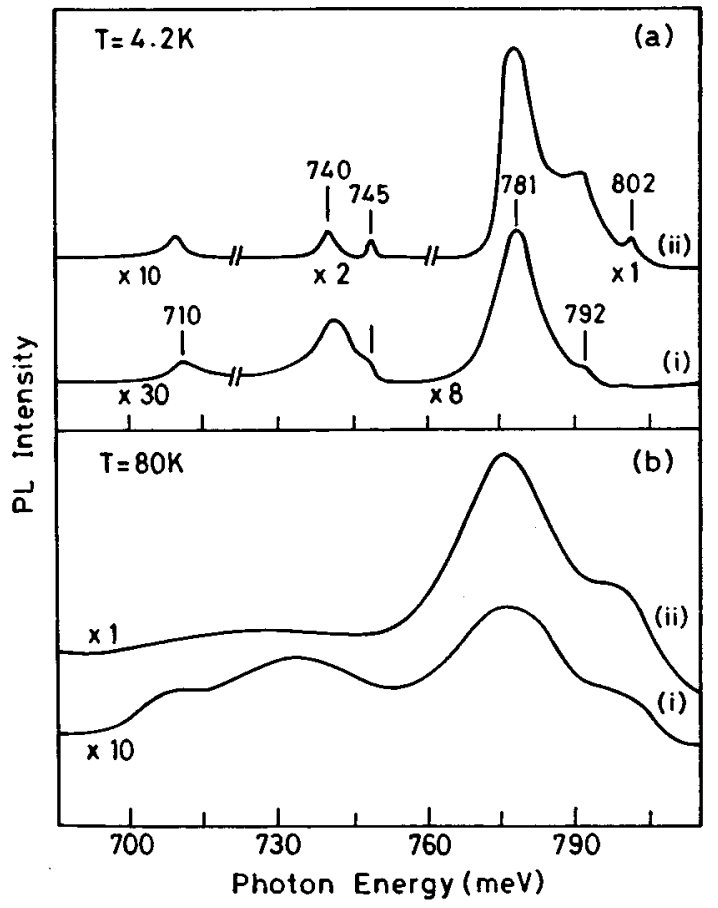

FIG. 7. PL spectra of Te-compensated $p$-GaSb recorded at (a) $4.2 \mathrm{~K}$ and (b) $80 \mathrm{~K}$ : (i) without an $a$-Si:H layer; (ii) with an $a$-Si:H layer.

band to the neutral state of the native acceptor level (Table I). As can be seen in Fig. 7(b), the intensity of the $704 \mathrm{meV}$ peak is higher than $775 \mathrm{meV}(781 \mathrm{meV}$ at $4.2 \mathrm{~K})$ in the unpassivated sample. However, in the passivated sample, the $704 \mathrm{meV}$ transition is very weak. The CL spectra shown in Fig. 4 also exhibited a similar nature. It should be noted that the trend observed here in the case of Te-compensated samples [Fig. 7(b)] is in contrast to what was observed for undoped samples [Fig. 6(b)] and requires further explanation.

The relative intensities of CL and PL transitions in various samples can be understood by the respective Fermi level position. For an uncompensated $p$-GaSb at $4.2 \mathrm{~K}$, the Fermi level is above the valence band edge and lies near the neutral state of the native acceptor level. With an increase in temperature, the Fermi level moves upward and crosses the shallow acceptor level. Thus the intensity of the $777 \mathrm{meV}$ transition quenches and the intensity of the deeper level (710 $\mathrm{meV}$ ) increases proportionately. The Fermi level can also be raised by counter doping with $n$-type dopants like Te, thus facilitating the transition from deeper levels. The temperature at which the PL intensity of the shallow level quenches would provide vital information regarding the Fermi level position and therefore to the degree of compensation.

The temperature-dependent PL intensities of $777 \mathrm{meV}$ (at $4.2 \mathrm{~K}$ ) and $710 \mathrm{meV}$ (at $4.2 \mathrm{~K}$ ) transitions in undoped $p$-GaSb before and after passivation are shown in Figs. 8(a) and 8(b), respectively. The fact that the intensity of the 777 $\mathrm{meV}$ transition quenches at a lower temperature in case of the passivated sample indicates that the Fermi level position in these samples is higher than that for the unpassivated sample. This can occur due to more effective passivation of 


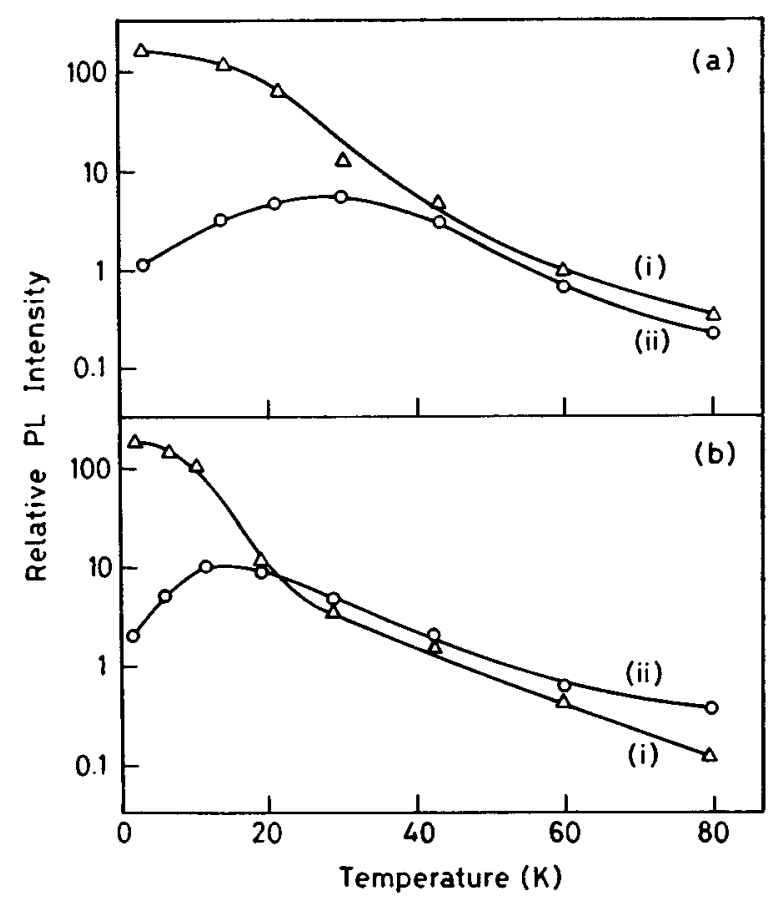

FIG. 8. Temperature dependence of PL intensities for (i) $777 \mathrm{meV}$ and (ii) $710 \mathrm{meV}$ transitions in undoped $p$-GaSb: (a) without an $a$-Si:H layer, (b) with an $a-\mathrm{Si}: \mathrm{H}$ layer.

the native acceptors than the unintentional donors which would lead to increased compensation and hence the rise in Fermi level position. This upward shift in the Fermi level position would account for the increase in relative PL intensity of the $704 \mathrm{meV}$ peak with respect to the $775 \mathrm{meV}$ transition seen in Fig. 6(b). For the Te-compensated samples, an opposite trend is observed as shown in Fig. 9 which is clearly due to more effective passivation of donors than the acceptors. As a result of effective passivation of Te donors, the Fermi level shifts down due to which the levels at 704 and $730 \mathrm{meV}$ are not seen in the CL spectra (Fig. 4). This downward shift in Fermi level position after passivation explains the decrease in relative PL intensity of the $704 \mathrm{meV}$ peak with respect to the $775 \mathrm{meV}$ shown in Fig. 7(b).

It is worth mentioning here that the donors are minority charges in $p$-GaSb and usually passivation of minority dopants is not common in III-V compounds. However, in heavily compensated materials or under conditions of minority carrier injection, one can observe minority dopant passivation. ${ }^{22-25}$ In previous studies on hydrogenated $\mathrm{Te}-\mathrm{Zn}$ codoped $n-\mathrm{GaSb}$, we have shown efficient passivation of the minority dopant. ${ }^{9}$ In the present study, the possibility of more efficient passivation of the Te donors compared to the native acceptors can be due to two reasons. First, tellurium is present in large concentration $\left(\sim 10^{17} \mathrm{~cm}^{-3}\right)$ in the sample. Second, the passivation efficiency is more for the hydrogenic defects like the Te donor rather than the native defect which act as heliumlike centers.

Last, the passivation efficiency of the nonradiative centers by hydrogen has been evaluated as a function of $a-\mathrm{Si}: \mathrm{H}$ deposition temperature. The CL intensity increases monotonically with increase in deposition temperature. This fact is

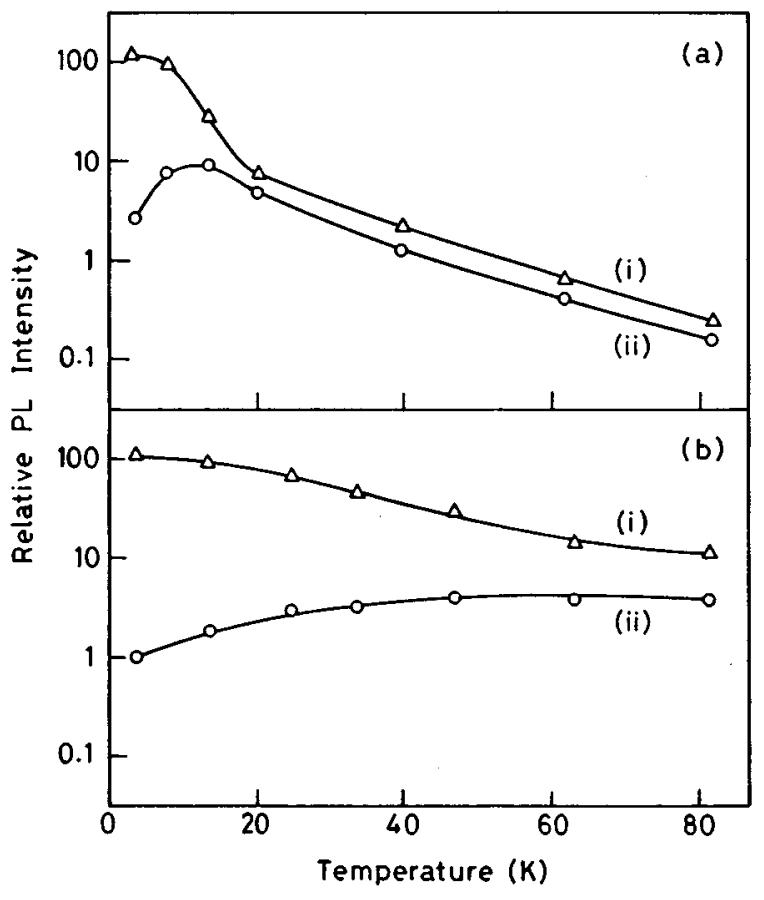

FIG. 9. Temperature dependence of PL intensities for (i) $781 \mathrm{meV}$ and (ii) $710 \mathrm{meV}$ transitions in Te-compensated $p$-GaSb: (a) without an $a$-Si:H layer, (b) with an $a$-Si:H layer.

also substantiated by the defect contrast in the CL images shown in Fig. 2. The PL intensity also increases with temperature initially, but shows a decreasing trend at higher temperature. ${ }^{26}$ The decrease in PL intensity for higher deposition temperatures is due to the increased absorption in the $a$-Si:H layer. ${ }^{27}$ When the correction for the absorption is accounted for, the PL intensity exhibits a similar trend as the CL intensity. This indicates that the passivation efficiency increases with increase in deposition temperature. The passivation of surface and bulk defects would certainly influence the electrical properties of the material. The details of the current transport properties of $\mathrm{GaSb}$ diodes fabricated with an interfacial $a-\mathrm{Si}: \mathrm{H}$ layer are presented elsewhere. ${ }^{28}$

\section{CONCLUSIONS}

In conclusion, we have investigated the CL and PL properties of $a$-Si:H coated undoped and Te-compensated $p$-GaSb. Efficient passivation of the surface as well as bulk defects up to $\sim 3 \mu \mathrm{m}$ is observed. An overall improvement in luminescence intensity by $\sim 20$ times and well-resolved excitonic features are observed as a result of bulk deep level passivation by hydrogen and the reduction of surface recombination centers by the $a$-Si:H layer, respectively. The passivation of shallow impurities in the bulk by hydrogen has been found to depend on the sample type. In undoped $p$-GaSb, a more efficient passivation of acceptors occurs. However, in Te-compensated $p$-GaSb, passivation of Te, the minority dopant is favored. The present study shows the passible effects of unintentional hydrogen passivation in $\mathrm{GaSb}$ during encapsulation with amorphous $\mathrm{Si}$. These dopant deactivation effects may be quite general and applicable for other 
semiconductors too, and can be expected especially when a hydrogen-containing plasma is employed for the surface deposition. From the technological point of view, this $a-\mathrm{Si}: \mathrm{H}$ layer deposition can be used as a single-step process by which both passivation of bulk defects by hydrogen plasma and a surface protective layer can be achieved. Furthermore, this process is compatible for large scale device fabrication.

\section{ACKNOWLEDGMENTS}

One of the authors (P.S.D.) would like to thank CSIR (India) for the award of a senior research fellowship. U.P. gratefully acknowledges MEC (Spain) for the postdoctoral fellowship. This work was partially supported by the Universidad Autonoma de Madrid, Spain, through a visiting scientist fellowship and by DGICYT Project Nos. PB93-1256 and ESP95-0148.

${ }^{1}$ B. J. Skromme, C. J. Sandroff, E. Yablonovitch, and T. Gmitter, Appl. Phys. Lett. 51, 2022 (1987).

${ }^{2}$ R. N. Nottenburg, C. J. Sandroff, D. A. Humphrey, T. H. Hollenbeck, and R. Bhat, Appl. Phys. Lett. 52, 218 (1988).

${ }^{3}$ L. Koenders, U. Blomachez, and W. Monch, J. Vac. Sci. Technol. B 6, 1416 (1988).

${ }^{4}$ S. J. Pearton, J. W. Corbett, and M. Stavola, Hydrogen in Crystalline Semiconductors (Springer, Heidelberg, 1992).

${ }^{5}$ P. S. Dutta, K. S. Sangunni, H. L. Bhat, and V. Kumar, Appl. Phys. Lett. 65, 1695 (1994).

${ }^{6}$ P. S. Dutta, K. S. R. Koteswara. Rao, H. L. Bhat, and V. Kumar, J. Appl. Phys. 77, 4825 (1995).

${ }^{7}$ A. G. Milnes and A. Y. Polyakov, Solid State Electron. 36, 803 (1993).

${ }^{8}$ P. S. Dutta, K. S. Sangunni, H. L. Bhat, and V. Kumar, Appl. Phys. Lett. 66, 1986 (1995).
${ }^{9}$ P. S. Dutta, K. S. Sangunni, H. L. Bhat, and V. Kumar, Phys. Rev. B 51, 2153 (1995).

${ }^{10}$ Hydrogenated Amorphous Silicon, Semiconductors and Semimetals, Vol. 21, edited by J. I. Pankove (Academic, New York, 1984), Parts A, B, C, and D.

${ }^{11}$ P. S. Dutta, H. L. Bhat, K. S. Sangunni, and V. Kumar, J. Cryst. Growth 141, 44 (1994).

${ }^{12}$ G. C. Dubey, R. A. Singh, S. N. Mukherjee, S. Pal, and M. G. Rao, Bull. Mater. Sci. 8, 267 (1986).

${ }^{13}$ F. Dominguez-Adame, J. Piqueras, and P. Fernandez, Appl. Phys. Lett. 58, 257 (1991).

${ }^{14}$ B. G. Yacobi and D. B. Holt, J. Appl. Phys. 59, R1 (1986).

${ }^{15}$ C. H. Gatos, J. J. Vaughan, J. Lagowski, and H. C. Gatos, J. Appl. Phys. 52, 1464 (1981).

${ }^{16}$ H. C. Casey, Jr. and J. S. Jayson, J. Appl. Phys. 42, 2774 (1971).

${ }^{17}$ K. Kanaya and S. Okayama, J. Phys. D 5, 43 (1972).

${ }^{18}$ G. Benz and R. Conradt, Phys. Rev. B 16, 843 (1977).

${ }^{19}$ A. I. Lebedev and I. A. Strel'nikova, Sov. Phys. Semicond. 13, 229 (1979).

${ }^{20}$ P. S. Dutta, K. S. R. Koteswara. Rao, H. L. Bhat, and V. Kumar, Appl. Phys. A 61, 149 (1995).

${ }^{21}$ V. Swaminathan and A. T. Macrander, Materials Aspects of GaAs and InP Based Structures (Prentice-Hall, Englewood Cliffs, NJ, 1991).

${ }^{22}$ C. H. Seager, R. A. Anderson, and D. K. Brice, J. Appl. Phys. 68, 3268 (1990).

${ }^{23}$ A. J. Tavendale, A. A. Williams, D. Alexiev, and S. J. Pearton, Mater. Res. Soc. Symp. Proc. 59, 469 (1986).

${ }^{24}$ A. J. Tavendale, D. Alexiev, and A. A. Williams, Appl. Phys. Lett. 47, 316 (1985).

${ }^{25}$ A. J. Tavendale, S. J. Pearton, A. A. Williams, and D. Alexiev, Appl. Phys. Lett. 56, 1457 (1990).

${ }^{26}$ P. S. Dutta, Ph.D. thesis, Indian Institute of Science, May 1995.

${ }^{27}$ E. Demichelis, E. Minetti-Mezetti, A. Tageiaferro, E. Tresso, P. Rava, and N. M. Ravindra, J. Appl. Phys. 59, 611 (1986).

${ }^{28}$ P. S. Dutta, A. K. Sreedhar, H. L. Bhat, G. C. Dubey, V. Kumar, and E. Dieguez, Appl. Phys. Lett. 67, 1001 (1995). 
Journal of Applied Physics is copyrighted by the American Institute of Physics (AIP). Redistribution of journal material is subject to the AIP online journal license and/or AIP copyright. For more information, see http://ojps.aip.org/japo/japcr/jsp

Copyright of Journal of Applied Physics is the property of American Institute of Physics and its content may not be copied or emailed to multiple sites or posted to a listserv without the copyright holder's express written permission. However, users may print, download, or email articles for individual use. 
Journal of Applied Physics is copyrighted by the American Institute of Physics (AIP). Redistribution of journal material is subject to the AIP online journal license and/or AIP copyright. For more information, see http://ojps.aip.org/japo/japcr/jsp 